\title{
E-cigarette advertisements, and associations with the use of e-cigarettes and disapproval or quitting of smoking: Findings from the International Tobacco Control (ITC) Netherlands Survey
}

Citation for published version (APA):

Nagelhout, G. E., Heijndijk, S. M., Cummings, K. M., Willemsen, M. C., van den Putte, B., Heckman, B. W., Hummel, K., de Vries, H., Hammond, D., \& Borland, R. (2016). E-cigarette advertisements, and associations with the use of e-cigarettes and disapproval or quitting of smoking: Findings from the International Tobacco Control (ITC) Netherlands Survey. International Journal of Drug Policy, 29, 73-79. https://doi.org/10.1016/j.drugpo.2015.12.015

Document status and date:

Published: 01/03/2016

DOI:

10.1016/j.drugpo.2015.12.015

Document Version:

Publisher's PDF, also known as Version of record

Document license:

Taverne

Please check the document version of this publication:

- A submitted manuscript is the version of the article upon submission and before peer-review. There can be important differences between the submitted version and the official published version of record. People interested in the research are advised to contact the author for the final version of the publication, or visit the DOI to the publisher's website.

- The final author version and the galley proof are versions of the publication after peer review.

- The final published version features the final layout of the paper including the volume, issue and page numbers.

Link to publication

\footnotetext{
General rights rights.

- You may freely distribute the URL identifying the publication in the public portal. please follow below link for the End User Agreement:

www.umlib.nl/taverne-license

Take down policy

If you believe that this document breaches copyright please contact us at:

repository@maastrichtuniversity.nl

providing details and we will investigate your claim.
}

Copyright and moral rights for the publications made accessible in the public portal are retained by the authors and/or other copyright owners and it is a condition of accessing publications that users recognise and abide by the legal requirements associated with these

- Users may download and print one copy of any publication from the public portal for the purpose of private study or research.

- You may not further distribute the material or use it for any profit-making activity or commercial gain

If the publication is distributed under the terms of Article 25fa of the Dutch Copyright Act, indicated by the "Taverne" license above,

Download date: 26 Apr. 2023 
Research paper

\title{
E-cigarette advertisements, and associations with the use of e-cigarettes and disapproval or quitting of smoking: Findings from the International Tobacco Control (ITC) Netherlands Survey
}

\author{
Gera E. Nagelhout ${ }^{\mathrm{a}, \mathrm{b}, *}$, Suzanne M. Heijndijk ${ }^{\mathrm{c}}$, K. Michael Cummings ${ }^{\mathrm{d}}$, \\ Marc C. Willemsen ${ }^{\mathrm{a}, \mathrm{c}}$, Bas van den Putte ${ }^{\mathrm{e}, \mathrm{f}}$, Bryan W. Heckman ${ }^{\mathrm{d}}$, Karin Hummel ${ }^{\mathrm{a}}$, \\ Hein de Vries ${ }^{\mathrm{a}}$, David Hammond ${ }^{\mathrm{g}}$, Ron Borland ${ }^{\mathrm{h}}$ \\ ${ }^{a}$ Department of Health Promotion, Maastricht University (CAPHRI), PO Box 616, 6200 MD Maastricht, The Netherlands \\ ${ }^{\mathrm{b}}$ Department of Family Medicine, Maastricht University (CAPHRI), PO Box 616, 6200 MD Maastricht, The Netherlands \\ ${ }^{\mathrm{c}}$ Dutch Alliance for a Smokefree Society, Eisenhowerlaan 108, 2517 KL The Hague, The Netherlands \\ ${ }^{\mathrm{d}}$ Department of Psychiatry and Behavioral Sciences, Medical University of South Carolina, 67 President Street, Charleston, South Carolina 29425, USA \\ e Department of Communication, University of Amsterdam (ASCoR), PO Box 15793, 1001 NG Amsterdam, The Netherlands \\ ${ }^{\mathrm{f}}$ Trimbos Institute, Netherlands Institute for Mental Health and Addiction, PO Box 725, 3500 AS Utrecht, The Netherlands \\ ${ }^{\mathrm{g}}$ School of Public Health and Health Systems, University of Waterloo, 200 University Avenue West, Waterloo N2L 3G1, Ontario, Canada \\ ${ }^{\mathrm{h}}$ Nigel Gray Fellowship Group, Cancer Council Victoria, 615 St Kilda Road, Melbourne, Victoria 3004, Australia
}

\section{A R T I C L E IN F O}

\section{Article history:}

Received 30 August 2015

Received in revised form 11 December 2015

Accepted 14 December 2015

\section{Keywords:}

Advertising

Denormalization

Electronic cigarettes

Netherlands

Smoking cessation

\begin{abstract}
A B S T R A C T
Background: Much attention has been directed towards the possible effects of e-cigarette advertisements on adolescent never smokers. However, e-cigarette advertising may also influence perceptions and behaviours of adult smokers. The aim of our study was to examine whether noticing e-cigarette advertisements is associated with current use of e-cigarettes, disapproval of smoking, quit smoking attempts, and quit smoking success.

Methods: We used longitudinal data from two survey waves of the ITC Netherlands Survey among smokers aged 16 years and older $(n=1198)$. Respondents were asked whether they noticed e-cigarettes being advertised on television, on the radio, and in newspapers or magazines in the previous 6 months. Results: There was a significant increase in noticing e-cigarette advertisements between 2013 (13.3\%) and 2014 (36.0\%), across all media. The largest increase was for television advertisements. There was also a substantial increase in current use of e-cigarettes (from 3.1\% to 13.3\%), but this was not related to noticing advertisements in traditional media ( $\mathrm{OR}=0.99, p=0.937$ ). Noticing advertisements was bivariately associated with more disapproval of smoking (Beta $=0.05, p=0.019$ ) and with a higher likelihood of attempting to quit smoking $(\mathrm{OR}=1.37, p=0.038)$, but these associations did not reach significance in multivariate analyses. There was no significant association between noticing advertisements and quit smoking success in either the bivariate or multivariate regression analysis (OR=0.92, $p=0.807)$.

Conclusion: Noticing e-cigarette advertisements increased sharply in the Netherlands between 2013 and 2014 along with increased e-cigarette use, but the two appear unrelated. The advertisements did not seem to have adverse effects on disapproval of smoking and smoking cessation.
\end{abstract}

(C) 2015 Elsevier B.V. All rights reserved.

\footnotetext{
* Corresponding author at: Department of Health Promotion, Maastricht University (CAPHRI), PO Box 616, 6200 MD Maastricht, The Netherlands.

E-mail addresses: gera.nagelhout@maastrichtuniversity.nl (G.E. Nagelhout), sanne.heijndijk@alliantienr.nl (S.M. Heijndijk), cummingk@musc.edu (K.M. Cummings), marc.willemsen@maastrichtuniversity.nl (M.C. Willemsen), S.J.H.M.vandenPutte@uva.nl (B. van den Putte), heckmanb@musc.edu (B.W. Heckman), karin.hummel@maastrichtuniversity.nl (K. Hummel), hein.devries@maastrichtuniversity.nl (H. de Vries), david.hammond@uwaterloo.ca (D. Hammond), ron.borland@cancervic.org.au (R. Borland).
} 


\section{Introduction}

Electronic cigarettes (also called e-cigarettes) aerosolize liquid mixtures that often contain nicotine, flavorants, and humectants (e.g. propylene glycol and/or vegetable glycerin). E-cigarette use significantly reduces the exposure to tobacco-related carcinogens and toxicants when used instead of regular cigarettes (McNeill, Brose, Calder, \& Hitchman, 2015). However, they are not harmless (Goniewicz et al., 2014; Rom, Pecorelli, Valacchi, \& Reznick, 2014). In many countries, advertising of e-cigarettes is not subject to the same restrictions as those imposed on the advertising of regular cigarettes. Advertising of e-cigarettes through media where tobacco advertising is no longer allowed - such as on the radio and on television - has attracted the attention and concern from health advocates. There are fears that such marketing may renormalize smoking and encourage adolescent never smokers to take up smoking (e.g. De Andrade, Hastings, \& Angus, 2013; Fairchild, Bayer, \& Colgrove, 2014; O’Dowd, 2014). However, the influence of advertising of e-cigarettes on adult smokers is often overlooked, while they are the primary target group of e-cigarette advertisements.

Advertisements for e-cigarettes frequently present these products as an alternative to regular cigarettes, that is cheaper and safer than cigarettes, can be used in places where smoking is not allowed, and may help to stop smoking (De Andrade, Hastings, Angus, Dixon, \& Purves, 2013; Richardson, Ganz, Stalgaitis, Abrams, \& Vallone, 2014; Richardson, Ganz, \& Vollone, 2014). Through such messages e-cigarette advertisements may not only stimulate smokers to use e-cigarettes, but also to quit smoking regular cigarettes, either using e-cigarettes instead or using them as a transition to complete abstinence from nicotine. There is also a possibility that e-cigarette advertisements may stimulate ecigarette use in conjunction with regular cigarettes, for example, using e-cigarettes where regular smoking is prohibited. Glamorous presentations of e-cigarettes in advertisements may increase approval of regular smoking because of the resemblance of cigarettes and e-cigarettes. However, it is also possible that advertisements that communicate that e-cigarettes are healthier and safer than regular cigarettes increase disapproval of regular smoking.

Various empirical studies examining the effects of e-cigarette advertisement exposure on adult smokers have emerged over the past two years. Cross-sectional studies that examined selfreported exposure to e-cigarette advertisements found that exposure was associated with more ever use of e-cigarettes (Harrington et al., 2014), more use of e-cigarettes because of health reasons (Harrington et al., 2014), and with more misconceptions about nicotine in e-cigarettes (Sanders-Jackson, Tan, Bigman, \& Henriksen, 2014). Exposure was not associated with perceived harm of secondhand vapour, but positive evaluation of the advertisements was associated with lower perceived harm of secondhand vapour (Tan, Bigman, Mello, \& Sanders-Jackson, 2015). Cross-sectional studies that exposed all participants to e-cigarette advertisements found that adult smokers reported an urge to smoke, thoughts about smoking, and thoughts about quitting after seeing the advertisements (Kim, Lee, Shafer, Nonnemaker, \& Makarenko, 2015), and that a positive evaluation of the advertisements was associated with more intention to use e-cigarettes (Trumbo \& Kim, 2015). Experimental studies among adult smokers have found that some e-cigarette advertisements elicit more interest in trying e-cigarettes (Pepper, Emery, Ribisl, Southwell, \& Brewer, 2014; Pepper, Ribisl, Emery, \& Brewer, 2014) and a greater urge to smoke tobacco (Maloney \& Cappella, 2015) than other e-cigarette advertisements. Also, an experimental study among adult smokers and non-smokers showed that exposure to e-cigarette advertisements was associated with more interest in e-cigarette trial than exposure to snus advertisements, particularly among smokers (Smith, Bansal-Travers, O'Connor, Goniewicz, \& Hyland, 2015). To the best of our knowledge, no longitudinal studies have examined effects of exposure to e-cigarette advertisements on adult smokers. Also, no studies examined effects of exposure to e-cigarette advertisements on disapproval of smoking and quitting smoking.

Although e-cigarettes have been on the Dutch market since 2007, advertising for these products was not allowed from January 2008 to June 2012. During this period, e-cigarette use remained low among Dutch tobacco smokers, but increased four-fold between 2013 (4\% current use) and 2014 (16\%) which corresponds to the time when e-cigarette advertisements started to appear on television (Hummel et al., 2015). Compared to other European countries, the Netherlands had the highest percentage of people who had seen e-cigarette advertisements in the past year in 2014 (69\% in the Netherlands compared to 39\% average in Europe; European Commission, 2015). This difference is particularly pronounced for noticing e-cigarette advertisements on television. Contrary to e-cigarette advertisements, tobacco advertisements are not allowed on Dutch television. The Dutch tobacco law allows advertising inside and outside specialized tobacco shops, but completely bans tobacco advertising from television, radio, newspapers and magazines (Heijndijk \& Willemsen, 2015). The ban on tobacco advertising does not apply to e-cigarettes because e-cigarettes are not regulated as tobacco products in the Netherlands. Tobacco smoking prevalence is slightly lower in the Netherlands (23\%) than in most other European countries (26\% on average) (European Commission, 2015).

In this paper, we present data from a longitudinal survey of a representative sample of adult tobacco smokers in the Netherlands followed between 2013 and 2014. We investigate the following research question: Is noticing advertisements for e-cigarettes associated with current use of e-cigarettes, disapproval of smoking, quit smoking attempts, and quit smoking success?

\section{Methods}

Sample

We used longitudinal data from two waves of the International Tobacco Control (ITC) Netherlands Survey. The cohort started in 2008 and included smokers aged 16 years and older who at enrollment smoked at least monthly and had smoked at least 100 factory-made cigarettes and/or roll-your-own cigarettes in their lives. The surveys were administered through the internet by the research firm TNS NIPO which used a quota sample of respondents from a large probability-based web database to get a sample that is representative of Dutch smokers (Nagelhout et al., 2010). Respondents received compensation for their participation in each survey by earning points for every answered question. The points could be exchanged for money, which ranged from five to seven Euros for each survey.

In the current study, we used data from the survey waves in May/June 2013 ('baseline survey') and May/June 2014 ('follow-up survey'). The baseline survey included 1970 respondents. For the follow-up survey, all respondents from baseline were recontacted of which 1607 participated (81.6\% retention). Given the focus of the current study on adult smokers, 352 cohort members were excluded because they were former smokers at the baseline survey of the present paper. Additionally, 57 respondents were excluded because they indicated to have used e-cigarettes at baseline, but indicated to have never used e-cigarettes in the past at follow-up, which is inconsistent. The final sample included 1198 respondents who were all smokers of factory-made and/or roll-your-own cigarettes at baseline. 
Measures

The questions used for the ITC Netherlands Survey were adapted from the conceptual model and questionnaire of the ITC Four Country Survey (Fong et al., 2006). All measures were assessed at both the baseline and the follow-up survey.

Noticing e-cigarette advertisements was assessed by asking "In the last 6 months, have you noticed e-cigarettes being advertised in any of the following places: On television? On radio? In newspapers or magazines?" Respondents could answer with "yes", "no", or "don't use television/radio/newspapers or magazines". The three items were combined into one dichotomous variable: did not notice e-cigarettes being advertised in any traditional media (0) versus did notice e-cigarettes being advertised in any traditional media (1).

Current use of e-cigarettes was assessed by asking "Have you ever tried using an electronic cigarette?" Respondents who answered "yes" were asked "How often do you currently use an electronic cigarette?" Respondents who answered that they currently used e-cigarettes at least monthly were considered current users (1) and respondents who used e-cigarettes less often or not at all were not considered current users ( 0 ) (Adkison et al., 2013; Hummel et al., 2015).

Disapproval of smoking was assessed with three statements: "Your family disapproves of smoking", "Your friends disapprove of smoking", and "Society disapproves of smoking". The last statement has been used in previous research (Hammond, Fong, Zanna, Thrasher, \& Borland, 2006) and the other ones were added to gain a more complete picture of disapproval of smoking in the social environment of respondents. Respondents could indicate whether they agreed with these statements on a five-point Likert scale ranging from "strongly disagree" (1) to "strongly agree" (5). A mean score of these statements was used as an index of disapproval of smoking (Cronbach's alpha $=0.63$ ).

Quit smoking attempts were measured with the question "Have you made any attempts to stop smoking since the last survey?" (Hyland et al., 2006). Respondents who answered "yes" were defined as having made a quit smoking attempt if they also indicated that this attempt started within the last six months (1) and otherwise were defined as not having made a quit smoking attempt within the last six months (0).

Quit smoking success was assessed by asking respondents who had attempted to quit in the last six months whether they were back to smoking or still stopped. Respondents who were still stopped or who were back to smoking but reported smoking less than once a month, were defined as having successfully quit smoking (1), while others were defined as not having successfully quit smoking (0) (Hyland et al., 2006).

Control variables (all as measured at baseline) were gender, age, education, regular cigarette smoking status, e-cigarette using status, noticing anti-tobacco information, and noticing advertisements for cessation medications. Age was categorized into 16-24, $25-39,40-54$, and 55 years and older. Education was categorized in three levels: low (primary education and lower prevocational secondary education), moderate (middle prevocational secondary education and secondary vocational education), and high (senior general secondary education, pre-university education, and higher professional education). Regular cigarette smoking status was categorized into daily smoker and non-daily smoker. E-cigarette using status was categorized into current user (at least monthly), past user, and never user. Noticing anti-tobacco information was assessed with the question "In the last 6 months, how often, if at all, have you noticed advertising or information that talks about the dangers of smoking, or encourages quitting?" Noticing advertisements for cessation medications was assessed with the question "In the last month, how often, if at all, have you noticed advertisements for cessation medications?" The last two questions could be answered on a four-point scale ranging from "never" $(0)$ to "often" (3).

\section{Ethics}

The ITC Netherlands Surveys were cleared for ethics by the Office of Research Ethics of the University of Waterloo in Canada.

\section{Analyses}

All analyses were performed with SPSS version 19.0 and were weighted by age and gender to be representative of tobacco smokers in the Netherlands. Differences between respondents who were followed-up and respondents who were not followed-up were tested with Chi-square tests and $t$-tests.

Bivariate and multivariate regression analyses were used to examine correlates of current use of e-cigarettes, quit smoking attempts, quit smoking success (all with logistic regression), and disapproval of smoking (with linear regression). For each dependent variable (except for quit smoking success) three models were estimated: (A) a bivariate model in which noticing advertisements for e-cigarettes in the last six months at followup were correlated with the dependent variables at follow-up, (B) a model that also adjusted for the baseline value of the dependent variable (this was not done for quit smoking success), and (C) a model that also adjusted for the above described control variables as measured at baseline and for the number of waves a respondent had participated in at follow-up since the cohort started in 2008 (to correct for 'time in sample' effects). In the analysis for quit smoking success it was not possible to adjust for the baseline value of the dependent variable, because all respondents were smokers (not quit or not quit successfully) at baseline.

\section{Results}

\section{Sample characteristics}

Table 1 shows the sample characteristics at baseline for the study sample $(n=1198)$ and the respondents who did not participate in the follow-up survey or who were excluded from the analyses $(n=772)$. Comparing both groups, respondents from the study sample were significantly older, they were less often high educated, more often current or past users of e-cigarettes, and more often noticed anti-tobacco information and advertisements for cessation medications. Respondents did not differ on noticing advertisements for e-cigarettes at baseline.

Detailed information about changes in e-cigarette using status and regular cigarette smoking status in our sample between baseline and follow-up is given in Table 2 (unweighted data). The large majority of the study sample had never used e-cigarettes at baseline $(82.2 \%)$ and still smoked regular cigarettes at follow-up (88.9\%). Overall, $29.4 \%$ tried e-cigarettes but were not using them at follow-up, while $13.7 \%$ were current e-cigarette users at followup. About half of the current e-cigarette users at baseline remained a current e-cigarette user at follow-up, while the other half stopped using e-cigarettes. More than eight out of ten current ecigarette users at follow-up were also smoking regular cigarettes at follow-up. Not shown in the table is that $34.9 \%$ of current ecigarette users at baseline and $42.1 \%$ of current e-cigarette users at follow-up were daily e-cigarette users.

\section{Noticing e-cigarette advertisements}

Table 3 shows that noticing e-cigarette advertisements increased significantly between baseline in 2013 (13.3\%) and 
Table 1

Differences in sample characteristics at baseline by whether respondents were followed up and included in the analyses or not (unweighted data).

\begin{tabular}{|c|c|c|c|}
\hline & $\begin{array}{l}\text { Respondents who were } \\
\text { followed up and included } \\
\text { in the analyses }(n=1198)\end{array}$ & $\begin{array}{l}\text { Respondents who were not } \\
\text { followed up or excluded from } \\
\text { the analyses }(n=772)\end{array}$ & \\
\hline \multicolumn{4}{|l|}{ Gender } \\
\hline Female (\%) & 49.3 & 48.2 & \multirow[t]{2}{*}{$\chi^{2}=0.25$} \\
\hline Male (\%) & 50.7 & 51.8 & \\
\hline \multicolumn{4}{|l|}{ Age group } \\
\hline $16-24$ years $(\%)$ & 17.2 & 15.4 & \multirow[t]{4}{*}{$\chi^{2}=26.48^{* * *}$} \\
\hline $25-39$ years $(\%)$ & 28.0 & 39.0 & \\
\hline $40-54$ years $(\%)$ & 26.5 & 23.2 & \\
\hline 55 years and older $(\%)$ & 28.2 & 22.4 & \\
\hline \multicolumn{4}{|l|}{ Educational level } \\
\hline Low (\%) & 26.4 & 23.2 & \multirow[t]{3}{*}{$\chi^{2}=14.10^{* * *+}$} \\
\hline Moderate (\%) & 47.2 & 42.5 & \\
\hline High (\%) & 26.4 & 34.3 & \\
\hline \multicolumn{4}{|l|}{ Regular cigarette smoking status (current smokers only) } \\
\hline Daily smoker of regular cigarettes (\%) & 90.7 & 90.4 & \multirow[t]{2}{*}{$\chi^{2}=0.02$} \\
\hline Non-daily smoker of regular cigarettes (\%) & 9.3 & 9.6 & \\
\hline \multicolumn{4}{|l|}{ E-cigarette using status } \\
\hline Current user of e-cigarettes (\%) & 3.6 & 0.6 & \multirow[t]{3}{*}{$\chi^{2}=61.08^{* * *}$} \\
\hline Past user of e-cigarettes (\%) & 14.2 & 4.2 & \\
\hline Never user of e-cigarettes (\%) & 82.2 & 95.2 & \\
\hline Noticed anti-tobacco information (M, SD) & $1.14(1.00)$ & $1.05(0.96)$ & $t=-2.03^{*}$ \\
\hline Noticed advertisements for cessation medications (M, SD) & $1.11(0.99)$ & $1.01(0.95)$ & $t=-2.26^{*}$ \\
\hline \multicolumn{4}{|l|}{ Noticed advertisements for e-cigarettes } \\
\hline Yes (\%) & 12.9 & 13.5 & \multirow[t]{2}{*}{$\chi^{2}=0.12$} \\
\hline No (\%) & 87.1 & 86.5 & \\
\hline
\end{tabular}

${ }^{*} p<0.05$.

*** $p<0.01$.

$p<0.001$.

Table 2

Current, past, and never use of e-cigarettes at baseline by regular cigarette smoking status and e-cigarette using status at follow-up (unweighted data).

\begin{tabular}{|c|c|c|c|c|}
\hline & $\begin{array}{l}\text { Current user of } \\
\text { e-cigarettes at } \\
\text { baseline }(n=43)\end{array}$ & $\begin{array}{l}\text { Past user of } \\
\text { e-cigarettes at } \\
\text { baseline }(n=170)\end{array}$ & $\begin{array}{l}\text { Never user of } \\
\text { e-cigarettes at } \\
\text { baseline }(n=984)\end{array}$ & $\begin{array}{l}\text { Total } \\
(n=1197)\end{array}$ \\
\hline Smoker of regular cigarettes and current user of e-cigarettes at follow-up (\%) & 41.9 & 16.5 & 9.8 & 11.9 \\
\hline Smoker of regular cigarettes and past user of e-cigarettes at follow-up (\%) & 44.2 & 74.7 & 17.5 & 26.6 \\
\hline Smoker of regular cigarettes and never user of e-cigarettes at follow-up (\%) & 0.0 & 0.0 & 61.4 & 50.5 \\
\hline Former smoker of regular cigarettes and current user of e-cigarettes at follow-up (\%) & 4.7 & 2.4 & 1.6 & 1.8 \\
\hline Former smoker of regular cigarettes and past user of e-cigarettes at follow-up (\%) & 9.3 & 6.5 & 1.9 & 2.8 \\
\hline Former smoker of regular cigarettes and never user of e-cigarettes at follow-up (\%) & 0.0 & 0.0 & 7.8 & 6.4 \\
\hline
\end{tabular}

Table 3

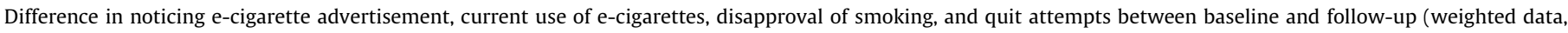
$n=1198$ ).

\begin{tabular}{|c|c|c|c|}
\hline & Baseline (May/June 2013) & Follow-up (May/June 2014) & \\
\hline Noticed e-cigarette advertisements (total) (\%) & 13.3 & 36.0 & $\chi^{2}=163.4^{* * *}$ \\
\hline Noticed e-cigarette advertisements on television (\%) & 6.6 & 27.4 & $\chi^{2}=181.28$ \\
\hline Noticed e-cigarette advertisements in newspapers or magazines (\%) & 8.2 & 16.7 & $\chi^{2}=17.43^{* * *}$ \\
\hline Noticed e-cigarette advertisements on the radio (\%) & 1.4 & 4.0 & $\chi^{2}=168.22^{* * *}$ \\
\hline Current use of e-cigarettes (\%) & 3.1 & 13.3 & $\chi^{2}=81.59^{* * *}$ \\
\hline Disapproval of smoking $(\mathrm{M}, \mathrm{SD})^{\mathrm{a}}$ & $3.08(0.77)$ & $3.12(0.79)$ & $t=-2.40$ \\
\hline Quit attempts (\%) & 12.7 & 19.2 & $\chi^{2}=18.67^{* * * *}$ \\
\hline
\end{tabular}

a On a scale from 1 to 5 .

${ }^{*} p<0.05$.

${ }^{* *} p<0.01$.

$p<0.001$.

follow-up in 2014 (36.0\%). The increase was especially large for noticing e-cigarette advertisements on television (from $6.6 \%$ to 27.4\%). Noticing e-cigarette advertisements on the radio also increased significantly, but remained very low (4.0\%) at follow-up.

\section{Use of e-cigarettes}

Table 3 shows that current use of e-cigarettes increased more than four-fold from $3.1 \%$ at baseline to $13.3 \%$ at follow-up one year later. As shown in Table 4, noticing e-cigarette advertisements in the last six months at follow-up was not significantly associated with current use of e-cigarettes at follow-up (Model 1C: OR = 0.99, $p=0.937$ ).

In additional analyses (not shown in tables) we examined whether noticing e-cigarette advertisements was associated with starting ever use of e-cigarettes between baseline and follow-up. This association was not significant, including when adjusting for all control variables $(\mathrm{OR}=0.86, p=0.332$ ). Noticing e-cigarette 
that the relationships may be more of those interested in quitting or disapproving of smoking being more likely to notice the advertisements, rather than the advertisements influencing disapproval of smoking or quit attempts.

From our results, it does not appear that exposure to e-cigarette advertising is having an adverse impact on disapproval of smoking and smoking cessation among adult smokers. We found no evidence to suggest advertising is encouraging smoking, with all trends in the opposite direction. Notably, concerns have focused primarily on the influence e-cigarette advertisements have on nonsmokers, especially adolescent never smokers (e.g. De Andrade, Hastings, \& Angus, 2013; Fairchild et al., 2014; O’Dowd, 2014), which we did not examine in the current study.

In a previous study, we hypothesized that the large increase in current use of e-cigarettes among Dutch smokers between 2013 and 2014 was a consequence of e-cigarette advertisements that started to appear on television (Hummel et al., 2015). Thus, the lack of association between noticing e-cigarette advertisements in traditional media and current use of e-cigarettes found in the current study was unexpected. Our results are also contrary to a previous cross-sectional study which found that exposure to ecigarette advertisements was associated with more ever use of ecigarettes (Harrington et al., 2014), and an experimental study which found that exposure to e-cigarette advertisements was associated with interest in e-cigarette trial (Smith et al., 2015). Possible alternative explanations for the increase in current use of e-cigarettes in the Netherlands are advertisements at points of sale and on the internet, media attention other than advertisements, seeing other people using e-cigarettes or talking about them, and an increase in e-cigarette stores. In the current study, we did not take into account exposure to sources of information about ecigarettes outside of advertisements (e.g. news stories), which are extensive, and could potentially have a more powerful influence on shaping attitudes and behaviours than product advertising. Therefore, future research should include exposure to different sources of messages about e-cigarettes.

Much of the use of e-cigarettes is experimental (or occasional use), rather than intensive continued use (Amato, Boyle, \& Levy, 2015; Pepper, Emery, et al., 2014; Pepper, Ribisl, et al., 2014). Our sample was not large enough to explore patterns within subgroups of current e-cigarette users. That said, we would expect the role of advertising to be most marked in stimulating experimental use. Experimental use may be more related to curiosity than to attempts to quit tobacco (Amato et al., 2015; Pepper, Emery, et al., 2014; Pepper, Ribisl, et al., 2014).

\section{Limitations}

We used longitudinal data to examine individual-level associations of noticing e-cigarette advertisements with changes in current use of e-cigarettes, disapproval of smoking, quit smoking attempts, and quit smoking success between baseline and followup. Interpretation of the observed associations needs to be treated with caution, but we can say with some certainty that there was no support for the hypothesis that e-cigarette advertising is undermining tobacco control efforts among adult smokers through decreasing disapproval of smoking, preventing quitting, or promoting relapse. We also warn that noticing advertisements is not the same as actual exposure. Exposure to advertisements may be forgotten by respondents, especially when not interested in the topic, but if this was so we might have seen significant positive associations with use of e-cigarettes. Also, we did not take the amount of exposure to advertising into account, so we could not test for dose-response relationships.

In the current study, all e-cigarette advertising was taken together. It is, however, possible that exposure to advertisements that communicate e-cigarettes are healthier and safer than regular cigarettes may increase disapproval of regular smoking, while advertisements that communicate that e-cigarettes are suitable for use in situations where smoke-free laws apply may decrease disapproval of regular smoking. Additionally, most television advertisements for e-cigarettes in the Netherlands have promoted the use of 'first generation' (small cigarette-like disposable or rechargeable) e-cigarettes, while promotion of 'new-generation' devices (with high-capacity batteries and electronic circuits that provide high energy to a refillable atomizer and do not resemble cigarettes) may have different effects.

Finally, not all respondents who participated in the survey in 2013 were successfully followed up in 2014. Respondents who were followed up were significantly more often part of the oldest age group, were less often high educated, more often current or past users of e-cigarettes, and they noticed anti-tobacco information and advertisements for cessation medications more often. Therefore, our findings may not be fully generalizable to the population of tobacco smokers in the Netherlands.

\section{Conclusion}

In the Netherlands, noticing e-cigarette advertisements increased sharply among Dutch tobacco smokers between 2013 and 2014, while current use of e-cigarettes also increased. However, noticing the advertisements did not seem to have influenced current use of e-cigarettes. Importantly, concerns that e-cigarette advertisements would decrease disapproval of smoking or would prevent smokers from attempting to quit or that they would promote relapse were not supported by our data.

\section{Funding}

The ITC Netherlands Surveys were supported by grants from the Netherlands Organisation for Health Research and Development (ZonMw) (\#200130002). A set of extra questions in the ITC Netherlands Survey wave 8 about alternative tobacco and nicotine products was funded by the National Cancer Institute and FDA Center for Tobacco Products (CTP) (\#3PO1CA138389-06S2). Bryan W. Heckman was supported by K12DA031794.

\section{Conflicts of interest statement}

KMC has received grant funding from the Pfizer, Inc., to study the impact of a hospital based tobacco cessation intervention. KMC also receives funding as an expert witness in litigation filed against the tobacco industry. The other authors declare that they have no conflicts of interest.

\section{References}

Adkison, S. E., O'Connor, R. J., Bansal-Travers, M., Hyland, A., Borland, R., Yong, H. H. et al. (2013). Electronic nicotine delivery systems: International Tobacco Control Four-country Survey. American Journal of Preventive Medicine, 44, 207-215.

Amato, M. S., Boyle, R. G., \& Levy, D. (2015). How to define e-cigarette prevalence? Finding clues in the use frequency distribution. Tobacco Control Published Online First: 17 June 2015

De Andrade, M., Hastings, G., \& Angus, K. (2013). Promotion of electronic cigarettes Tobacco marketing reinvented? BMJ, 347, f7473.

De Andrade, M., Hastings, G., Angus, K., Dixon, D., \& Purves, R. (2013). The marketing of electronic cigarettes in the UK. London: Cancer Research UK.

European Commission (2015). Special Eurobarometer 429: Attitudes of Europeans towards tobacco and electronic cigarettes. Brussels: European Commission.

Fairchild, A. L., Bayer, R., \& Colgrove, J. (2014). The renormalization of smoking? Ecigarettes and the tobacco "Endgame". New England Journal of Medicine, 370, 293-295.

Fong, G. T., Cummings, M., Borland, R., Hastings, G., Hyland, A., Giovino, G. A., et al. (2006). The conceptual framework of the International Tobacco Control (ITC) Policy Evaluation Project. Tobacco Control, 15(Suppl. 3), 3-11. 
Goniewicz, M. L., Knysak, J., Gawron, M., Kosmider, L., Sobczak, A., Kurek, J., et al. (2014). Levels of selected carcinogens and toxicants in vapour from electronic cigarettes. Tobacco Control, 23, 133-139.

Hammond, D., Fong, G. T., Zanna, M. P., Thrasher, J. F., \& Borland, R. (2006). Tobacco denormalization and industry beliefs among smokers from four countries. American Journal of Preventive Medicine, 31, 225-232.

Harrington, K. F., Hull, N., Akindoju, O., Kim, Y.-I., Hendricks, P. S., Kohler, C., et al. (2014). Electronic cigarette awareness, use history, and expected future use among hospitalized cigarette smokers. Nicotine \& Tobacco Research, 16, 1512-1517.

Heijndijk, S. M., \& Willemsen, M. C. (2015). Dutch tobacco control: Moving towards the right track? FCTC shadow report 2014 The Hague: Dutch Alliance for a Smokefree Society.

Hummel, K., Hoving, C., Nagelhout, G. E., De Vries, H., Van den Putte, B., Candel, M. J. J M., et al. (2015). Prevalence and reasons for use of electronic cigarettes among smokers: Findings from the International Tobacco Control (ITC) Netherlands Survey. International Journal of Drug Policy, 26, 601-608.

Hyland, A., Borland, R., Li, Q., Yong, H.-H., McNeill, A., Fong, G. T., et al. (2006) Individual-level predictors of cessation behaviours among participants in the International Tobacco Control (ITC) four country survey. Tobacco Control, 15(Suppl. 3), 83-94.

Kim, A. E., Lee, Y. O., Shafer, P., Nonnemaker, J., \& Makarenko, O. (2015). Adult smokers receptivity to a television advert for electronic nicotine delivery systems. Tobacco Control, 24, 132-135.

Maloney, E. K., \& Cappella, J. N. (2015). Does vaping in e-cigarette advertisements affect tobacco smoking urge, intensions, and perceptions in daily, intermittent and former smokers? Health Communication Published Online First: 11 March 2015.

McNeill, A., Brose, L. S., Calder, R., \& Hitchman, S. C. (2015). E-cigarettes: An evidence update. A report commissioned by Public Health England. London: Public Health England.

Nagelhout, G. E., Willemsen, M. C., Thompson, M. E., Fong, G. T., Van den Putte, B., \& De Vries, H. (2010). Is web interviewing a good alternative to telephone interviewing?
Findings from the International Tobacco Control (ITC) Netherlands Survey. BMC Public Health, 10, 351.

O'Dowd, A. (2014). Doctors criticise new advertising rules that allow celebrities to endorse e-cigarettes. BMJ, 349, g6180

Pepper, J. K., Emery, S. L., Ribisl, K. M., Southwell, B. G., \& Brewer, N. (2014). Effects of advertisements on smokers' interest in trying e-cigarettes: The roles of product comparison and visual cues. Tobacco Control, 23(Suppl. 3), 31-36.

Pepper, J. K., Ribisl, K. M., Emery, S. L., \& Brewer, N. T. (2014). Reasons for starting and stopping electronic cigarette use. International Journal of Environmental Research and Public Health, 11, 10345-10361.

Richardson, A., Ganz, O., Stalgaitis, C., Abrams, D., \& Vallone, D. (2014). Noncombustible tobacco product advertising: How companies are selling the new face of tobacco. Nicotine E Tobacco Research, 16, 606-614.

Richardson, A., Ganz, O., \& Vollone, D. (2014). Tobacco on the web: Surveillance and characterization of online tobacco and e-cigarette advertising. Tobacco Control Published Online First: 14 February 2014.

Rom, O., Pecorelli, A., Valacchi, G., \& Reznick, A. Z. (2014). Are e-cigarettes a safe and good alternative to cigarette smoking? Annals of the New York Academy of Sciences, $1340,65-74$

Sanders-Jackson, A. N., Tan, A. S. L., Bigman, C. A., \& Henriksen, L. (2014). Knowledge about e-cigarette constituents and regulation: Results from a national survey of U.S. young adults. Nicotine E Tobacco Research Published Online First: 26 December 2014.

Smith, D. M., Bansal-Travers, M., O'Connor, R. J., Goniewicz, M. L., \& Hyland, A. (2015). Associations between perceptions of e-cigarette advertising and interest in product trial amongst US adult smokers and non-smokers: Results from an internetbased pilot survey. Tobacco Induced Diseases, 13, 14.

Tan, A. S. L., Bigman, C. A., Mello, S., \& Sanders-Jackson, A. (2015). Is exposure to ecigarette communication associated with perceived harms of e-cigarette secondhand vapour? Results from a national survey of US adults. BMJ Open, 5, e007134.

Trumbo, C. W., \& Kim, S.-J. (2015). The effect of electronic cigarette advertising on intended use among college students. Addictive Behaviors, 46, 77-81. 